\title{
Professional Community Honors TMS Members; TMS Meets with Congressional Leaders
}

\section{member news}

Share the good news about your professional accomplishments in the pages of JOM. Contact Lynne Robinson, Magazine Editor, JOM, at Irobinson@tms.org with your information. Please note that only current TMS members can submit items for consideration to Member News.

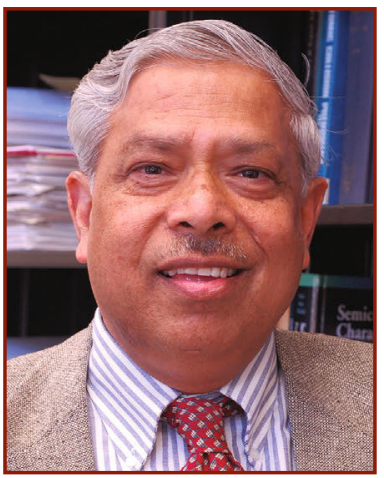

Jagdish (Jay) Narayan

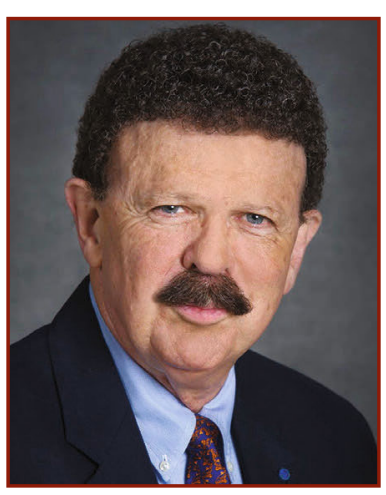

Robert Ritchie

\section{Jay Narayan Inducted in National Academy of Engineering}

Jagdish (Jay) Narayan, a 1999 TMS Fellow, added induction into the U.S. National Academy of Engineering (NAE) to his long list of accomplishments. Membership in the NAE honors professionals who have led distinguished careers and made outstanding contributions to their fields. Election to the NAE is among the highest professional distinctions that an engineer can attain. Narayan will be formally inducted into the NAE during a ceremony on October 8, 2017, in Washington, D.C.

Narayan is the John C. C. Fan Family Distinguished Chair in Materials Science at North Carolina State University. He is also a Distinguished Visiting Scientist for Oakridge National Laboratory and director for the National Science Foundation (NSF) Center for Advanced
Materials and Smart Structures. A TMS life member, his many awards and recognitions include receiving the 2014 Institute of Metals/Robert Franklin Mehl Award and the 2011 Acta Materialia Gold Medal.

Narayan has made fundamental contributions in defects, diffusion, ion implantation, and laser-solid interactions. His work recently achieved a new milestone by significantly increasing the temperature at which carbon-based materials act as superconductors, using a novel, boron-doped Q-carbon material. The previous record for superconductivity in boron-doped diamond was 11 Kelvin, or -439.87 degrees Fahrenheit. Narayan's boron-doped Q-carbon was superconductive at 37 Kelvin, which is $-393.07$.

\section{Robert Ritchie Elected to Royal Society}

Robert O. Ritchie, H.T. and Jessie Chua Distinguished Professor of Engineering at the University of California, Berkeley, has been elected as a foreign member of the Fellows of the Royal Society. He was cited for his "research into the mechanics and micro-mechanisms of fracture and fatigue of a broad range of structural and biological materials, where he has provided a microstructural basis for their damage-tolerance and fatigue resistance." Ritchie is also a senior faculty scientist sat the Lawrence Berkeley National Laboratory.
A 2004 TMS Fellow, Ritchie also counts the 1985 AIME Champion H. Mathewson Award, the 2010 Institute of Metals/Robert Franklin Mehl Award, the 2014 Acta Materialia Gold Medal, the 2017 Morris Cohen Award among his many other awards and honors.

The Royal Society is the independent scientific academy of the United Kingdom dedicated to promoting excellence in science. Ritchie is also a fellow of the U.S. National Academy of Engineering, the Russian Academy of Sciences, and the Royal Swedish Academy of Engineering. 


\section{Ainissa Ramirez Honored for Communications Excellence}

Ainissa G. Ramirez, Science Evangelist received the 2017 Norm Augustine Award for Outstanding Achievement in Engineering Communications from the American Association of Engineering Societies (AAES). She was honored for "her clear passion to make engineering and science understandable to young people and the general public enabled by a splendid talent to communicate in an articulate, engaging, and meaningful manner via social media, the web, books, periodicals, and broadcasting." Ramirez was nominated for the award by TMS through the American Institute of Mining, Metallurgical and Petroleum Engineers (AIME), a member society of AAES.

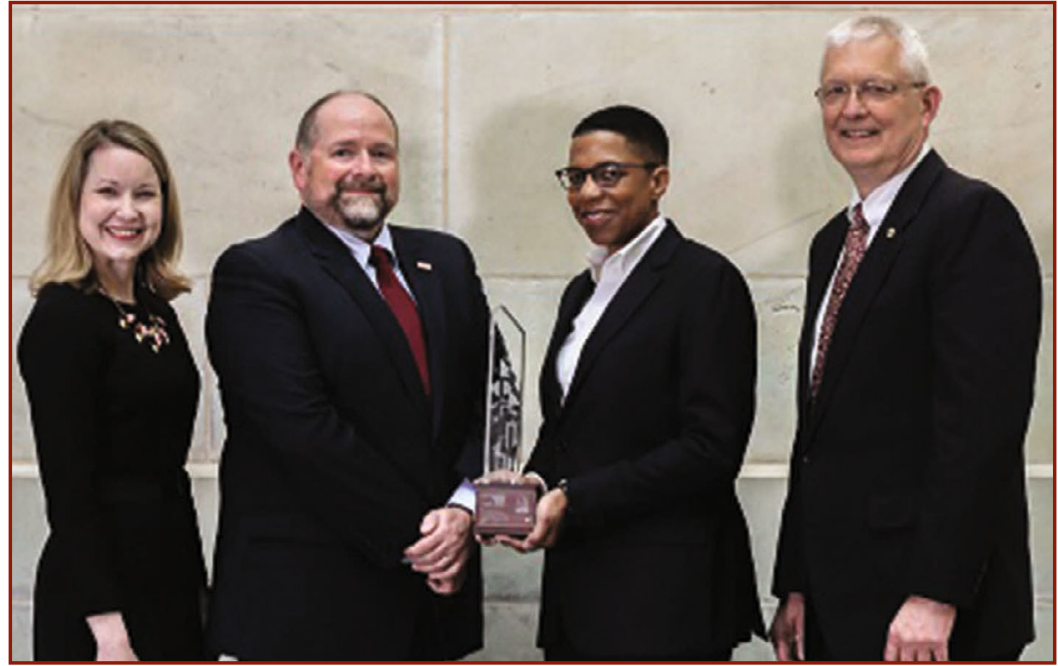

Ainissa Ramirez was formally recognized with the Norm Augustine Award at the AAES Award Banquet on April 24. Pictured at the ceremony (from left): Alyse Stofer, Chair, AAES; James Robinson, TMS Executive Director; Ramirez; David DeYoung, 2017 TMS President. Photo Credit: Granted Photography

\section{TMS Representatives Meet with Congressional Leaders}

Discouraging funding cuts for scientific research and encouraging fewer barriers to international travel for scientific collaboration were among the topics that 2017 TMS President David DeYoung and TMS Executive Director James J. Robinson discussed with U.S. congressional leaders in April. These conversations focused on three main points:

- Discourage Potential Funding Cuts for Federal Agencies and Scientific Research: TMS representatives underscored the importance of government investment is science and technology and urged congressional leaders to reject proposed budget cuts to federal science agencies and scientific research.

- Promote Visa Issuance and Immigration within the Science and Engineering Community: TMS encouraged congressional leaders to give special attention to any decisions that could put the United States in the position of unnecessarily losing access to valuable science and engineering talent from around the world.

- Make Use of our Technical Expertise: TMS offered itself as a resource to help Congressional leaders connect with scientific experts and locate expert witnesses to help inform them in developing legislation and making science policy decisions.

As a follow up to the visits, TMS issued a message to U.S. President Donald Trump this week on the value of international scientific collaboration, the historical contributions of immigrants to the U.S. science and technology enterprise, and the importance of scientists being able to travel into and out of the United States. The letter can be accessed in the Public \& Governmental Affairs section of the TMS website.

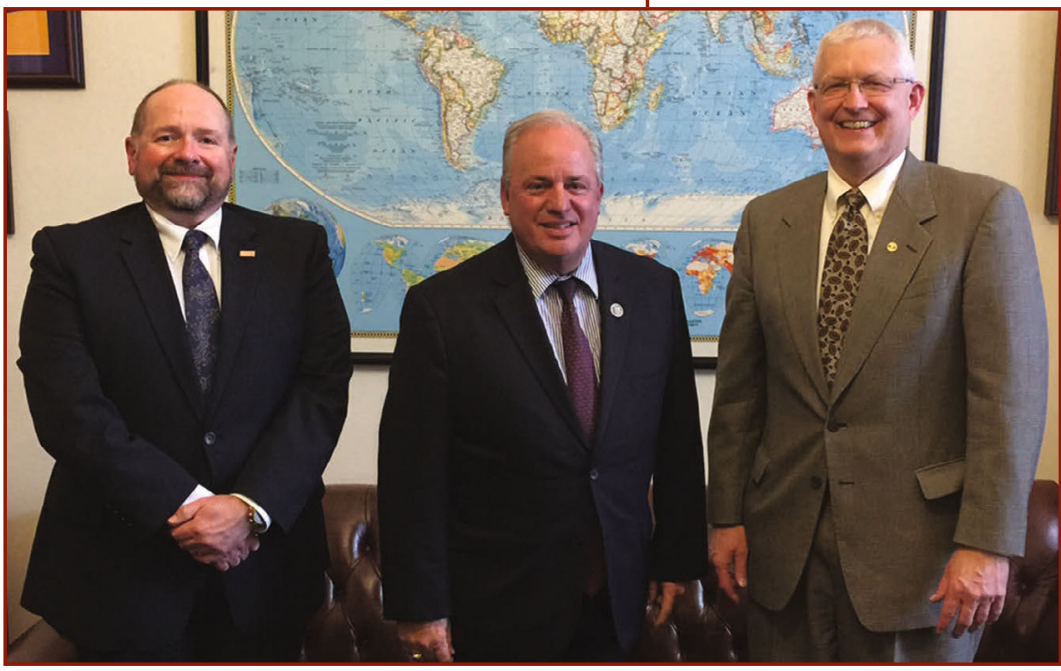

Pictured during a busy day of Congressional visits are from left: TMS Executive Director James Robinson, Congressman Mike Doyle (D-PA), and 2017 TMS President David DeYoung. 